\title{
Algoritmo para el manejo de la obstrucción nasal en neonatos y lactantes
}

\author{
Algorithm for the management of nasal obstruction in \\ neonates and infants
}

\author{
Dr. Hugo Rodríguez ${ }^{a}$, Dra. Giselle Cuestas ${ }^{b}$, Dr. Máximo Rodríguez D’Aquilac y \\ Dr. Juan A. Rodríguez D'Aquila
}

\section{RESUMEN}

La causa principal de obstrucción nasal en el neonato y en el lactante es la rinitis inflamatoria o infecciosa. Con menor frecuencia, puede ser de origen congénito, neoplásico, traumático o iatrogénico. Eselpediatraquienalertaráantesignos y síntomas de patologías menos frecuentes pero graves que deben diagnosticarse precozmente. Presentamos una propuesta dealgoritmo sencillo para el manejo de la obstrucción nasal unilateral y bilateral en neonatos y lactantes. Describimos las patologías que ocasionan insuficiencia ventilatoria nasal con más frecuencia o que revisten importancia por su gravedad, sus síntomas orientadores para el diagnóstico presuntivo, los estudios complementarios y el tratamiento.

a. Servicio de

Endoscopía

Respiratoria

Hospital de

Pediatría "Prof. Dr.

Juan P. Garrahan".

Ciudad Autónoma de Buenos Aires,

Buenos Aires, Argentina.

b. Servicio de Otorrinolaringología Infantil, Hospital Italiano de Buenos Aires. Ciudad Autónoma de Buenos Aires, Buenos Aires, Argentina.

c. Fundación Arauz. Buenos Aires, Argentina.

d. Centro OIR. Ramos Mejía, Buenos Aires, Argentina.

Correspondencia: Dra. Giselle Cuestas, giselle_cuestas@yahoo. com.ar

\section{Financiamiento:}

Ninguno.

Conflicto de intereses:

Ninguno que declarar.

Recibido: 12-2-2016

Aceptado: 20-4-2016
Palabras clave: Algoritmos, obstrucción nasal, neonatos, lactantes.

\begin{abstract}
The main cause of nasal obstruction in neonates and infants is inflammatory or infectious rhinitis. Congenital, neoplastic, traumatic or iatrogenic causes are less frequent. The pediatrician will alert to signs and symptoms of diseases less common but serious which should be diagnosed early.

We present a proposal of simple algorithm for the management of unilateral and bilateral nasal obstruction in neonates and infants. We describe the pathologies that cause nasal respiratory failure, either those that occur very often or those which are important for their severity, their guiding symptoms to the presumptive diagnosis, additional studies and treatment.

Key words: Algorithms, nasal obstruction, neonates, infants.
\end{abstract}

http:/ /dx.doi.org/10.5546/aap.2016.477

\section{GENERALIDADES}

Toda patología que ocasiona insuficiencia ventilatoria nasal en el neonato y en el lactante tendrá repercusión no solo en la respiración, sino también en la deglución, en la voz, en el sueño, en el desarrollo cráneo-facial y en el crecimiento pondoestatural.
La manifestación clínica depende de la edad, la causa de la insuficiencia, la lateralidad (unilateral o bilateral), el modo de aparición (brusca o progresiva), el grado de obstrucción nasal (parcial o total) y la duración (transitoria o permanente).

Los neonatos son respiradores nasales obligados hasta las primeras 4-6 semanas de vida. Esto se debe a que la laringe del recién nacido presenta una posición elevada, con la epiglotis casi en contacto con el paladar blando, lo que dificulta el pasaje del aire a través de la cavidad bucal, excepto durante el llanto. Por lo tanto, la obstrucción nasal completa puede llevar a consecuencias graves, como dificultad respiratoria y retraso del crecimiento. ${ }^{1}$

Son numerosas las causas de insuficiencia ventilatoria nasal en los neonatos y los lactantes. La principal es la rinitis. Dentro de las causas congénitas, las más frecuentes son la atresia de coanas (AC), la estenosis congénita de la apertura piriforme (ECAP), el quiste dermoide, el glioma y el encefalocele. Mientras que la obstrucción nasal bilateral, a menudo, se presenta en el período neonatal, la obstrucción nasal unilateral puede hacerlo más tarde en la vida.

Los signos y síntomas típicos de obstrucción nasal son el cornaje (es el ruido ocasionado por el pasaje del aire en forma turbulenta a través de fosas nasales con calibre disminuido), la rinorrea, la dificultad respiratoria (aleteo nasal, retracción torácica, cianosis cíclica), la apnea obstructiva, la alteración en la alimentación, la epífora, el retraso del crecimiento, 
la aerofagia con distensión abdominal, la deformidad nasal externa y el llanto hiponasal. ${ }^{1,2}$

El diagnóstico debe efectuarse mediante una exhaustiva anamnesis y examen físico. Se sospecha obstrucción nasal ante la falta de movimiento de una brizna de algodón o la ausencia de empañamiento de un espejo, colocado bajo las narinas mientras la boca está cerrada, y frente a la imposibilidad o dificultad de introducir una sonda por la fosa nasal. Se puede realizar una rinoscopía anterior utilizando el otoscopio y completar la evaluación con una endoscopía nasal con óptica rígida o flexible. Esto permitirá determinar el sitio de obstrucción e identificar la causa. Los estudios por imágenes son de utilidad en ciertos casos para el diagnóstico diferencial. Se comienza por la radiografía de cavum y de senos paranasales, que tiene una limitada utilidad (hipertrofia adenoidea, cuerpos extraños). El tratamiento médico y/o quirúrgico será diferente dependiendo de la causa y de la gravedad de los síntomas.

En los algoritmos propuestos, mencionamos las causas principales de obstrucción nasal en el recién nacido y en el lactante para ayudar al pediatra en la pronta evaluación, en el diagnóstico certero y en el tratamiento adecuado (Figuras 1 y 2).

\section{Obstrucción nasal unilateral \\ Cuerpo extraño}

Si bien la obstrucción unilateral de las fosas nasales en niños es causada, principalmente, por la introducción de un cuerpo extraño (CE), los $\mathrm{CE}$ intranasales no son frecuentes en los recién nacidos y lactantes. A esta edad, siempre se debe pensar en la posibilidad de que haya sido introducido por un tercero, aunque la capacidad de aprehensión está presente desde los 8 meses y hay una tendencia natural a introducirse

FIGURA 1. Algoritmo para el manejo de la obstrucción nasal unilateral en neonatos y lactantes

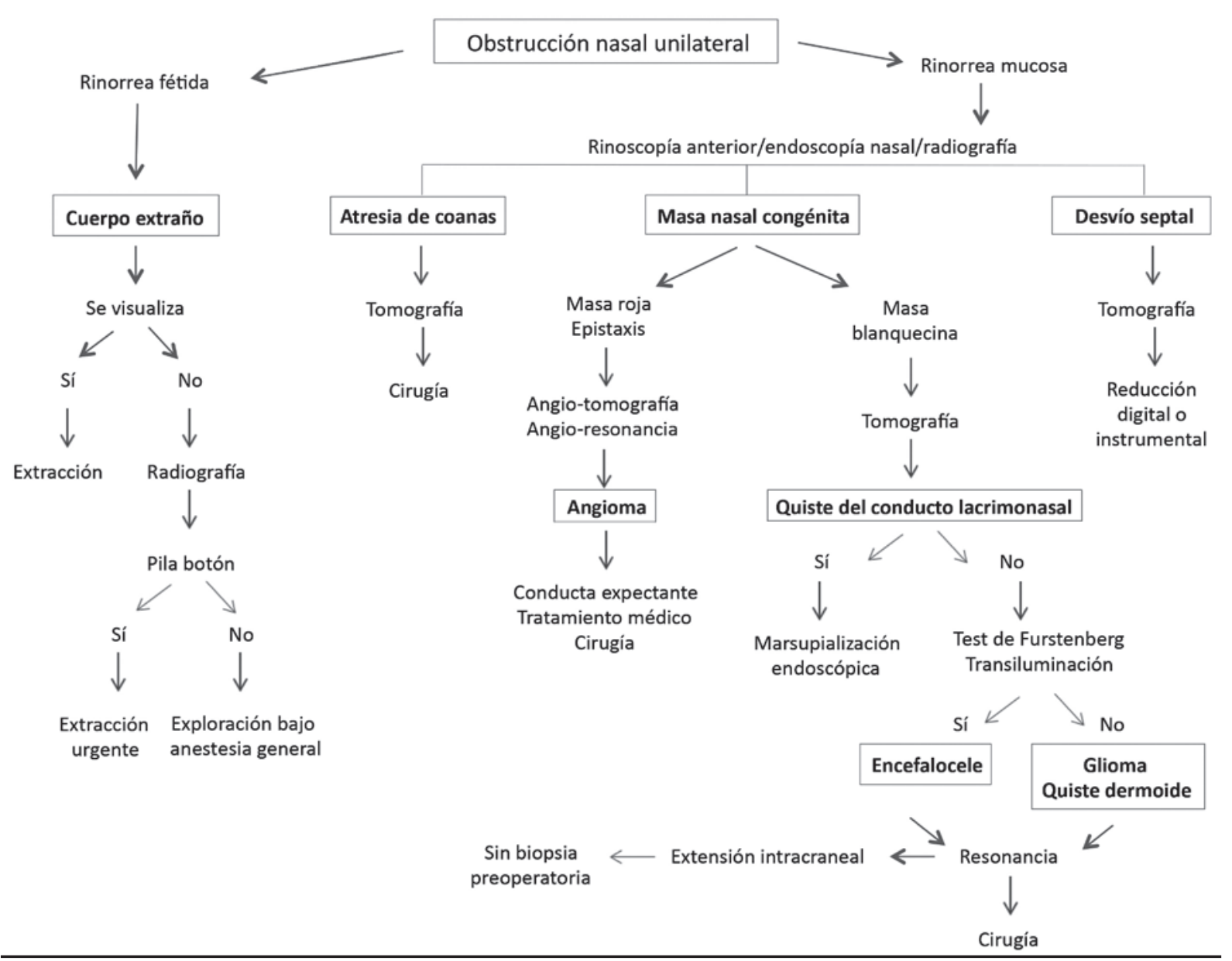


objetos por los orificios naturales de la cara. Se manifiesta con rinorrea unilateral y olor fétido. El diagnóstico se confirma mediante una rinoscopía anterior, utilizando un espéculo nasal o auricular, o empujando la nariz hacia arriba con el pulgar. El endoscopio rígido o flexible puede ser de utilidad para revelar el CE. A veces, el edema y el sangrado ocultan el objeto.

Es fundamental diferenciar la pila botón de otro tipo de CE, ya que esta constituye una urgencia, debido a la gravedad y precocidad de las lesiones que produce. Se recomienda realizar una radiografía simple de senos paranasales y cavum cuando no existe certeza del tipo de CE y el resultado positivo agilizaría el acceso a una exploración bajo anestesia general. La presencia de doble contorno es imagen indicativa de pila botón $^{3}$ (Figura 3.A). El tratamiento ideal se basa en la extracción delicada del CE por el orificio nasal. La anestesia general debe ser considerada ante la falta de colaboración del paciente, la imposibilidad de visualizar el objeto o si está profundamente enclavado. ${ }^{4}$

\section{Atresia de coanas unilateral}

Es la anomalía congénita nasal más común. Se caracteriza por la obliteración de la apertura nasal posterior. Se estima que la incidencia en Argentina es de uno por cada 70000 nacidos vivos. ${ }^{5}$ Se puede presentar aislada o como parte de síndromes, por ejemplo, el CHARGE (coloboma, heart defect, atresia choanae, retarded growth and development, genital abnormality, and ear abnormality; acrónimo de coloboma, cardiopatías, AC, retraso del crecimiento, hipoplasia genital, anomalías óticas). Es más frecuente en el sexo femenino y la placa atrésica más común es la unilateral derecha. Mientras que la atresia bilateral se presenta en el nacimiento y constituye una urgencia médica, la unilateral lo hace, por lo general, entre los 5 y los 24 meses. Se manifiesta con insuficiencia ventilatoria y rinorrea unilateral posicional

FIGURA 2. Algoritmo para el manejo de la obstrucción nasal bilateral en neonatos y lactantes

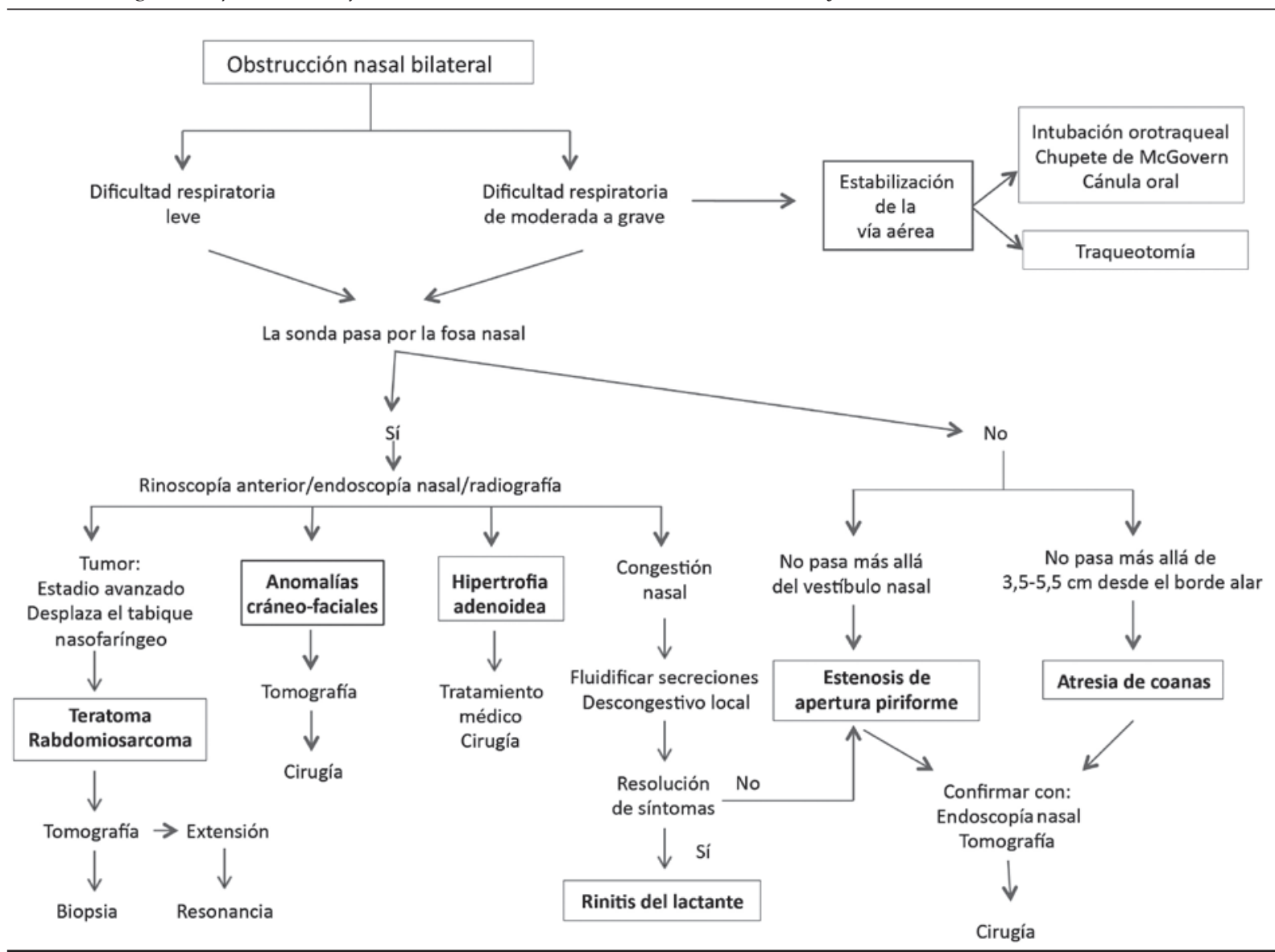


(aumenta al inclinar la cabeza hacia delante). El diagnóstico se sospecha ante la imposibilidad de introducir una sonda nasogástrica y se confirma mediante un examen endoscópico nasal y una tomografía computarizada (TC) de macizo cráneo-facial (MCF) (Figura 3.B). En la mayoría de los casos, la placa es mixta (componentes óseo y membranoso) y, en menor proporción, ósea. El tratamiento es quirúrgico y se puede retrasar hasta los 12 meses cuando no hay serios problemas respiratorios ni de alimentación. Se han descrito diferentes técnicas para la corrección quirúrgica de la AC; el abordaje de elección es el endonasal. ${ }^{5,6}$

\section{Desviación septal}

En el recién nacido, puede observarse la lateralización de la porción anterior de la pirámide nasal por luxación del septum cartilaginoso debida a la compresión de la nariz durante el embarazo o por traumatismo durante el parto vaginal. La rinoscopía y la endoscopía permiten observar el desvío anterior y /o posterior del tabique, respectivamente. La TC del MCF permite evaluar el componente cartilaginoso u óseo de la desviación (Figura 3.C). En el neonato, la reducción instrumental o digital es sencilla y debe realizarse inmediatamente. En las desviaciones de origen traumático, cuando se diagnostica dentro de las primeras 48 horas de haberse producido el traumatismo, se indica la reducción inmediata instrumental o quirúrgica. Pasado ese tiempo o cuando el origen de la desviación del septum nasal es malformativo, en la infancia, solo se recurre a la cirugía correctora (septoplastia) cuando la desviación provoca insuficiencia ventilatoria nasal total. 7,8
Masas nasales congénitas

$\mathrm{Su}$ incidencia se estima en 1 de cada 20 000-40 000 recién nacidos. La mayoría son relativamente benignas, pero no debe subestimarse su potencial para producir desfiguración y destrucción de la base del cráneo. Los síntomas de presentación pueden comenzar desde el nacimiento o pasar desapercibidos y ser un hallazgo en un examen pediátrico de rutina. $\mathrm{Al}$ momento del examen físico, se observa la falta de ventilación unilateral asociada o no a rinorrea y, en algunos casos, deformidad en el dorso nasal. La rinoscopía anterior puede poner de manifiesto el tumor si este alcanza el tercio anterior de la fosa nasal. Cuando se observa un "pólipo nasal" en un neonato, un lactante o en la primera infancia, debe pensarse en la posibilidad de estas afecciones (Figura 4). Los diagnósticos diferenciales más frecuentes son el quiste dermoide, el glioma, el encefalocele, el hemangioma y el quiste del conducto nasolagrimal. Antes de biopsiar o resecar una masa nasal, es muy importante excluir una extensión intracraneal. Los estudios por imágenes son de utilidad para aproximar al diagnóstico y excluir una extensión intracraneal. Son fundamentales la TC, para evaluar los elementos óseos (como defectos de la lámina cribosa y el hueso frontal), y la resonancia magnética, para evaluar los tejidos blandos y la existencia de comunicación intracraneal. ${ }^{8-11}$

El dacriocistocele es la dilatación quística del conducto lacrimonasal debida a su obstrucción. En general, es unilateral y más frecuente en el sexo femenino. Se presenta como una masa quística que ocupa el piso de la fosa nasal a nivel del meato inferior y desplaza el cornete inferior hacia arriba. El diagnóstico se confirma

Figura 3. Causas de obstrucción nasal unilateral. A. Cuerpo extraño intranasal: radiografía de perfil de cráneo donde se observa el doble halo de la pila botón. B y C. Tomografía computada, corte axial. B. Atresia de coanas unilateral derecha. C. Desviación septal. D. Tomografía computada, corte coronal y axial. Dacriocistocele congénito derecho

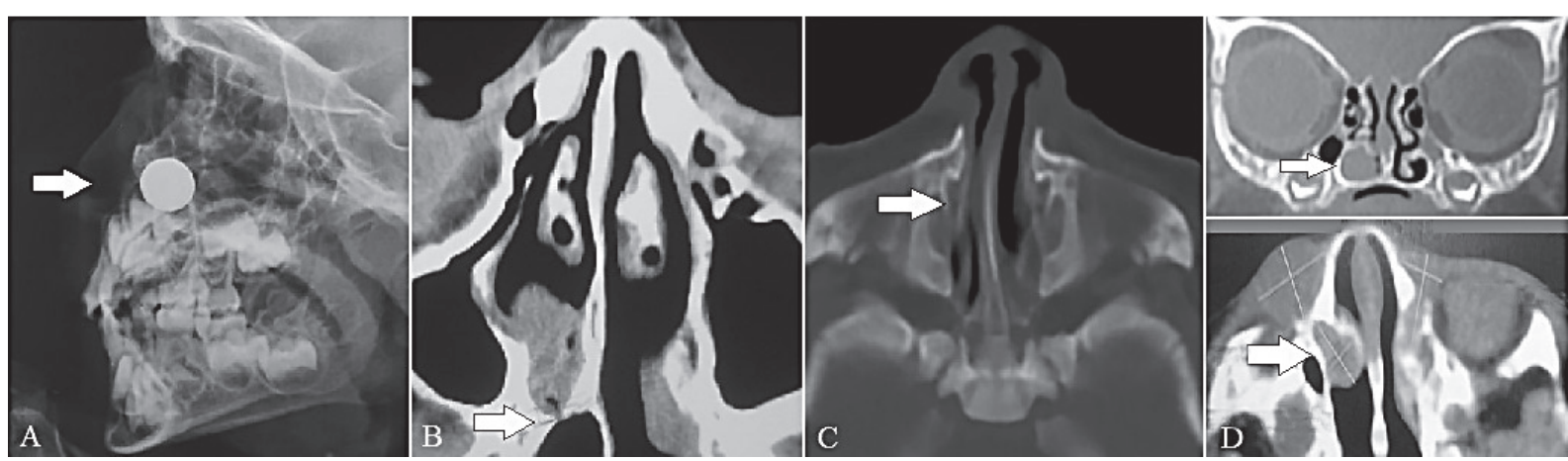


por TC (Figura 3.D). Cuando es pequeño, tiende a resolverse espontáneamente. Si no se resuelve y es sintomático, el tratamiento consiste en la marsupialización endoscópica del quiste junto con el sondaje del conducto lacrimonasal. , $^{811,12}$

El angioma es una masa roja intensa sangrante que suele manifestarse en la segunda semana de vida y crece hasta el año; después comienza una etapa de involución. Se ubica, preferentemente, en la mucosa que recubre el tabique nasal. Los estudios de imágenes con contraste complementan el diagnóstico. El tratamiento puede ser médico (corticoides y/o propranolol) o quirúrgico (resección de la lesión con electrocauterio o láser) ${ }^{8,11}$

El quiste dermoide es una fístula o quiste que afecta la pirámide nasal. Tiene contenido sebáceo y detritus celulares. A veces, se percibe por la presencia de uno o dos pelos. Se ubica en la línea media del dorso nasal. El 20\% tiene prolongación a la base del cráneo anterior. El glioma nasal está formado por tejido glial displásico heterotópico. Puede asociarse a hipertelorismo y ensanchamiento del dorso nasal por expansión tumoral y presentar conexión intracraneal. Se percibe firme con la palpación. Puede ser intra o extranasal. El tratamiento del quiste dermoide y del glioma nasal es la remoción completa de la lesión; considerando su extensión, pueden requerir abordaje neuroquirúrgico. ${ }^{8,10,11}$

El encefalocele es la eventración de las meninges (meningocele) o de las meninges y el parénquima cerebral (meningoencefalocele) cubierta por la mucosa del techo de la fosa nasal debido a un defecto en el cierre del neuroporo anterior. Es un tumor pulsátil, reductible y

Figura 4. Masas nasales congénitas. A. Deformidad en el dorso de la nariz por glioma nasal. B. Tumor nasal congénito que protruye de la fosa nasal derecha (lipoma). C. Tomografía computada, corte sagital. Glioma nasal. D. Angiotomografía, corte axial. Angioma nasal
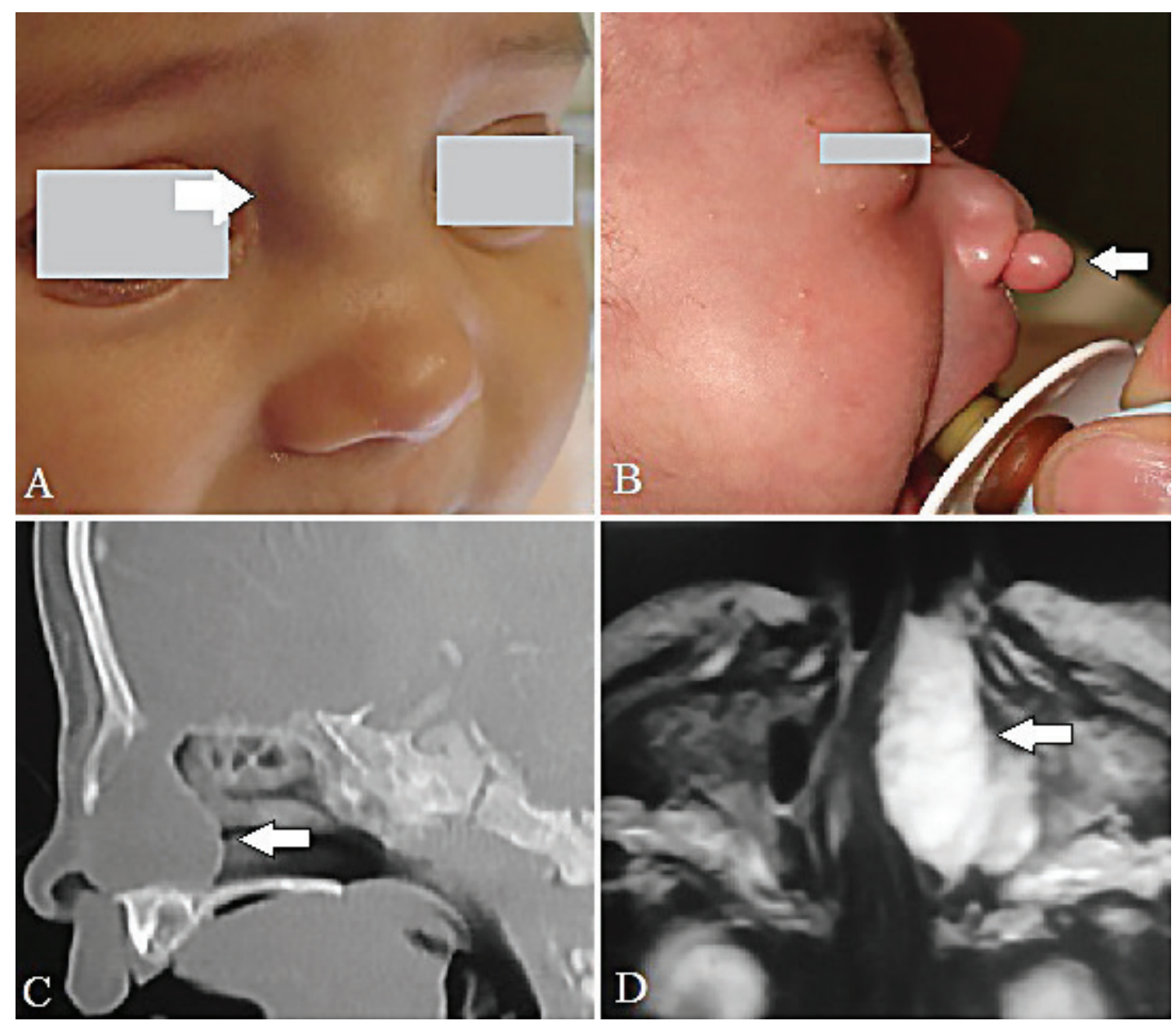
transiluminable. Aumenta de tamaño con el llanto o las maniobras de Valsalva o Furstenberg (compresión de la vena yugular homolateral). Se debe evitar realizar punciones o biopsias preoperatorias por el riesgo de pérdida de líquido cefalorraquídeo y de infección. El tratamiento es neuroquirúrgico. ${ }^{8,10,11}$

\section{Obstrucción nasal bilateral}

Debido a su respiración nasal obligada, el recién nacido con obstrucción nasal bilateral puede presentar dificultad respiratoria grave. Estos casos requieren la estabilización inmediata de la vía aérea, la cual puede realizarse mediante chupete de McGovern, cánula oral o intubación orotraqueal. La traqueotomía se reserva para situaciones en las que otras anomalías cráneofaciales están asociadas o si hay otros sitios de obstrucción (glosoptosis, estenosis laríngea). El tratamiento definitivo depende de la causa de la obstrucción.

\section{Anomalías cráneo-faciales}

Dentro de las patologías que afectan el desarrollo del macizo facial, se destacan los síndromes de Apert, Pfeiffer y Crouzon. La característica fundamental que determina la dificultad respiratoria en estos síndromes es la hipoplasia del tercio medio facial, que resulta en la disminución del diámetro anteroposterior de la nasofaringe asociada a cavidades nasales estrechas. Si la obstrucción es grave, es necesaria la traqueotomía. La resolución definitiva mediante avance del tercio medio facial se realiza en forma diferida. ${ }^{8}$

\section{Rinitis del lactante}

Es la principal causa de obstrucción nasal en esta edad. Consiste en la inflamación de la mucosa nasal, frecuentemente, de origen viral o inespecífico. Los síntomas típicos son la respiración ruidosa y la dificultad respiratoria que empeoran durante la succión, la rinorrea y la dificultad en la alimentación. El lactante se presenta afebril e irritable, sin alteraciones sistémicas. Elevando la punta de la nariz y con adecuada iluminación o con la óptica, se observará la congestión de la mucosa nasal y la rinorrea mucosa. El tratamiento es sintomático y procura mantener las fosas nasales permeables mediante drenaje postural (decúbito ventral) e instilaciones en goteo de solución fisiológica estéril y gotas descongestivas tópicas si fuese necesario. Es importante no aspirar las fosas nasales en forma reiterada con sondas de aspiración, ya que se puede generar mayor inflamación o lesionar la mucosa, lo que da lugar a la formación de sinequias.

\section{Atresia de coanas bilateral}

Se manifiesta con dificultad respiratoria desde el nacimiento. El neonato presenta disnea y cianosis, que pueden aliviarse con el llanto (ventilación cíclica de Richardson). Se sospecha

Figura 5. Causas de obstrucción nasal bilateral. Tomografía computada, corte axial. A. Atresia de coanas bilateral. B. Estenosis congénita de la apertura piriforme

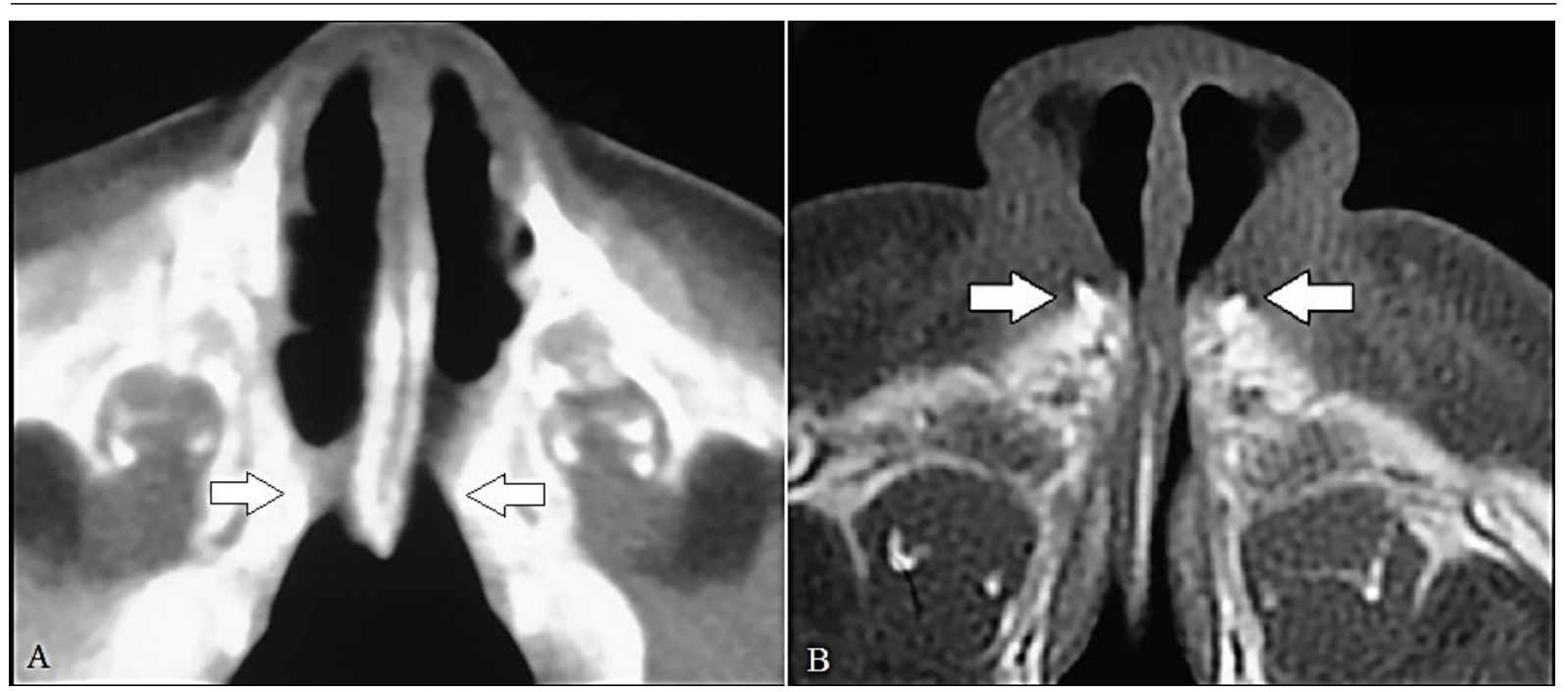


AC frente a la imposibilidad de introducir una sonda de 8 French $(2,7 \mathrm{~mm}$ de diámetro) más allá de 3,5-5,5 cm desde el borde alar. En el examen físico, la rinoscopía anterior muestra mucosa y cornetes de color pálido en la fosa nasal afectada y presencia de secreciones acumuladas que no drenan a la rinofaringe. El diagnóstico se confirma mediante un examen endoscópico de las fosas nasales y una TC del MCF, donde se observa tipo, espesor y localización de la placa atrésica (Figura 5.A). Los casos bilaterales requieren estabilización expedita de la vía aérea y alimentación con sonda orogástrica. El tratamiento definitivo es quirúrgico y se recomienda en los primeros días de vida. La reparación quirúrgica transnasal bajo visión endoscópica o microscópica se ha convertido, en la actualidad, en el procedimiento de elección y ha desplazado al abordaje transpalatino. ${ }^{5,6}$

\section{Estenosis congénita de la apertura piriforme}

Es una causa poco frecuente de obstrucción en el neonato producto del crecimiento óseo excesivo del proceso nasal medial del hueso maxilar de forma bilateral. Se ha descrito la asociación con megaincisivo (incisivo único central maxilar), holoprosencefalia, agenesia hipofisaria y alteraciones cromosómicas, entre otros. El síntoma más habitual es el cornaje. Otros posibles síntomas son la dificultad respiratoria, los trastornos de la deglución y la cianosis cíclica que mejora con el llanto. Al momento del examen físico, existe imposibilidad o dificultad de pasar una sonda K30 (2,8 mm de diámetro) más allá del vestíbulo nasal. El diagnóstico se confirma por TC del MCF, donde se observa la disminución del área nasal en la entrada ósea, mientras que las coanas son de calibre normal (Figura 5.B). Los casos leves se tratan de forma conservadora con descongestivos locales y humidificación hasta que la cavidad nasal crezca y la obstrucción desaparezca. En caso de dificultad respiratoria de moderada a grave, trastorno de la deglución y ante el fracaso de métodos conservadores, el tratamiento es quirúrgico y consiste en el ensanchamiento de la apertura piriforme mediante abordaje sublabial., ${ }^{2,13,14}$

\section{Hipertrofia adenoidea}

Es una de las causas más comunes de obstrucción nasal en el niño y es menos frecuente en el lactante. La adenoides se hace evidente a partir de los ocho meses de vida aproximadamente e involuciona hacia los ocho años. ${ }^{7}$ La hipertrofia adenoidea resulta en la obstrucción del pasaje nasal, bloqueo del aclaramiento adecuado del moco, disfunción de las trompas de Eustaquio y trastornos del desarrollo del macizo facial (fascies adenoidea). Habitualmente, la hipertrofia adenoidea va acompañada de hipertrofia amigdalina y se presenta con ronquido $y$, con frecuencia, con apneas nocturnas. La radiografía de cavum, con la boca cerrada y no en hiperextensión, permite evaluar la hipertrofia adenoidea. Una alternativa es la nasofibroscopía, forma más directa de evaluar el tamaño y la ubicación del tejido hipertrófico. La infección sobreagregada (adenoiditis) aumenta el tamaño de las vegetaciones adenoideas, la cual, mediante el tratamiento con corticoides nasales y antibióticos, puede retrogradar. Cuando el bloqueo nasal es total, la indicación es quirúrgica. Hay situaciones intermedias que deberá evaluar el especialista.

\section{Tumores}

Otra causa de obstrucción nasal bilateral son los tumores benignos y malignos que desplacen el tabique nasal, presenten estadio avanzado o se localicen en la rinofaringe.

El teratoma nasofaríngeo es un tumor raro formado por elementos tisulares derivados de las tres hojas embrionarias, los cuales no se hallan normalmente en el sitio de aparición del tumor. La mayoría son benignos, bien encapsulados y no presentan conexión intracraneal. El tratamiento es quirúrgico. Los niveles de $\alpha$-fetoproteína se miden periódicamente para evaluar la recurrencia. ${ }^{11} \mathrm{El}$ rabdomiosarcoma es un tumor maligno derivado de las células mesenquimales precursoras del músculo estriado. El subtipo histológico principal es el embrionario. El tratamiento dependerá de la estadificación del tumor, que incluye, dentro de las modalidades terapéuticas, cirugía, quimioterapia y/o irradiación. ${ }^{15}$

\section{CONCLUSIÓN}

La obstrucción nasal en neonatos y lactantes presenta gravedad variable, desde dificultad respiratoria leve con la alimentación hasta obstrucción grave de la vía aérea.

El diagnóstico diferencial es amplio y requiere una minuciosa anamnesis, examen físico, endoscopía nasal y/o estudios por imágenes para el diagnóstico certero y el tratamiento adecuado.

Los algoritmos que presentamos aportan un ordenamiento sencillo, que pensamos serán de utilidad para guiar al pediatra en el manejo de 
la obstrucción nasal en neonatos y lactantes, que incluye una gran cantidad de patologías que se deberán considerar al momento de establecer el diagnóstico diferencial. Estos algoritmos podrán ser adaptados a las condiciones de cada institución de acuerdo con los recursos disponibles, la complejidad de los pacientes y la presencia de personal con experiencia.

\section{REFERENCIAS}

1. Gnagi SH, Schraff SA. Nasal obstruction in newborns. Pediatr Clin North Am 2013;60(4):903-22.

2. Zanetta A, Rodríguez H, Cuestas G, Tiscornia C. Cornaje del recién nacido por estenosis congénita de la apertura piriforme. Serie de casos. Arch Argent Pediatr 2010;108(6):552-5.

3. Guidera AK, Stegehuis HR. Button batteries: the worst case scenario in nasal foreign bodies. N Z Med J 2010; 123(1313):68-73.

4. Rodríguez H, Cuestas G. Cuerpos extraños en oídos y fosas nasales, extracción. En Iñón A, Vázquez Estévez J, ed. Urgencias en pediatría. Manual de procedimientos. Buenos Aires: Panamericana; 2015:141-9.

5. Rodríguez H, Cuestas G, Passali D. Experiencia de 20 años en el tratamiento microquirúrgico de la atresia de coanas. Acta Otorrinolaringol Esp 2014;65(2):85-92.

6. Kim H, Park JH, Chung H, Han DH, et al. Clinical features and surgical outcomes of congenital choanal atresia: factors influencing success from 20-year review in an institute. $A m$ J Otolaryngol 2012;33(3):308-12.

7. Merediz A, Bernáldez P. Insuficiencia ventilatoria nasal.En MacriCN, Teper A, ed. Enfermedades respiratorias pediátricas. México: Mc Graw Hill Interamericana; 2003:339-50.

8. Lusk RP. Nasal and pharyngeal lesions. En Holinger LD, Lusk RP, Green CG, ed. Pediatric laryngology and bronchoesophagology. Philadelphia: Lippincott-Raven; 1997:117-35.

9. Zanetta A, Cuestas G, Oviedo M, Tiscornia C. Obstrucción nasal unilateral en niños. Síndrome de Pai. Arch Argent Pediatr 2011;109(5):e100-3.

10. François M, de Gaudemar I, Elmaleh M. Tumores benignos de la nariz y de los senos. Encyclopédie MédicoChirurgicale. Elsevier 2000:E-20-400-A-10.

11. Elluru RG, Wootten CT. Congenital malformations of the nose. En Flint PW, Haughey BH, Lund VJ, Niparkd JK, et al, ed. Cummings Otolaryngology. Head and Neck Surgery. $5^{\text {th }}$ ed. Philadelphia: Mosby; 2010:2686-96.

12. Lecavalier M, Nguyen LH. Bilateral dacryocystoceles as a rare cause of neonatal respiratory distress: report of 2 cases. Ear Nose Throat J 2014;93(1):E26-8.

13. Gimeno-HernándezJ,Iglesias-MorenoMC, Gómez-Serrano M, Poch-Broto J. Estenosis congénita del orificio piriforme y megaincisivo central único. Acta Otorrinolaringol Esp 2010;61(6):455-8.

14. Wormald R, Hinton-Bayre A, Bumbak P, Vijayasekaran S. Congenital nasal pyriform aperture stenosis $5.7 \mathrm{~mm}$ or less is associated with surgical intervention: a pooled case series. Int J Pediatr Otorhinolaryngol 2015;79(11):1802-5.

15. Cervini AB, Buján MM, Pierini AM. Rabdomiosarcomas en la infancia. Dermatol Argent 2012;18(6):433-41. 